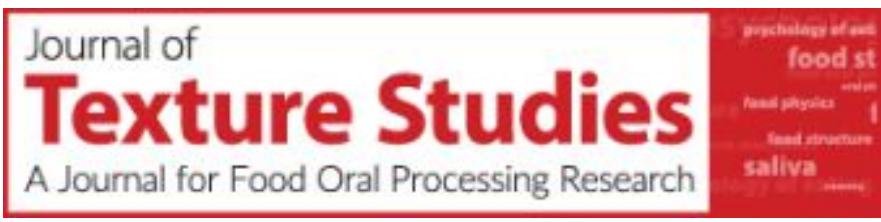

\title{
Release of updated International Dysphagia Diet Standardisation Initiative Framework (IDDSI 2.0)
}

\begin{tabular}{|c|c|}
\hline Journal: & Journal of Texture Studies \\
\hline Manuscript ID & JTS-2823.R1 \\
\hline Manuscript Type: & Letter to the Editor \\
\hline $\begin{array}{r}\text { Date Submitted by the } \\
\text { Author: }\end{array}$ & $n / a$ \\
\hline Complete List of Authors: & $\begin{array}{l}\text { Cichero, Julie; International Dysphagia Diet Standardisation Initiative, } \\
\text { Board of Directors; University of Queensland, School of Pharmacy, } \\
\text { Pharmacy Australia Centre of Excellence (PACE) } \\
\text { Lam, Peter; International Dysphagia Diet Standardisation Initiative, } \\
\text { Board of Directors; The University of British Columbia, Faculty of Land } \\
\text { and Food Systems; Peter Lam Consulting } \\
\text { Chen, Jianshe; International Dysphagia Diet Standardisation Initiative, } \\
\text { Board of Directors; Zhejiang Gongshang University, School of Food } \\
\text { Science and Biotechnology } \\
\text { Dantas, Roberto; International Dysphagia Diet Standardisation Initiative, } \\
\text { Board of Directors; University of Sao Paulo Clinics Hospital of the Faculty } \\
\text { of Medicine of Ribeirao Preto, Ribeirao Preto Medical School } \\
\text { Duivestein, Janice; International Dysphagia Diet Standardisation } \\
\text { Initiative, Board of Directors; Access Community Therapists; The } \\
\text { University of British Columbia, Faculty of Medicine } \\
\text { Hanson, Ben; International Dysphagia Diet Standardisation Initiative, } \\
\text { Board of Directors; UCL, Mechanical Engineering } \\
\text { Kayashita, Jun; International Dysphagia Diet Standardisation Initiative, } \\
\text { Board of Directors; Prefectural University of Hiroshima, Department of } \\
\text { Health Sciences } \\
\text { Pillay, Mershen; International Dysphagia Diet Standardisation Initiative, } \\
\text { Board of Directors; University of KwaZulu-Natal; Manchester } \\
\text { Metropolitan University } \\
\text { Riquelme, Luis; International Dysphagia Diet Standardisation Initiative, } \\
\text { Board of Directors; New York Medical College; NewYork-Presbyterian } \\
\text { Brooklyn Methodist Hospital } \\
\text { Steele, Catriona; International Dysphagia Diet Standardisation Initiative, } \\
\text { Board of Directors; University Health Network, KITE - Toronto } \\
\text { Rehabilitation Institute; University of Toronto Faculty of Medicine, } \\
\text { Department of Speech-Language Pathology, Rehabilitation Sciences } \\
\text { Institute } \\
\text { Vanderwegen, Jan; International Dysphagia Diet Standardisation } \\
\text { Initiative, Board of Directors; Thomas More University of Applied } \\
\text { Sciences, Department of Speech, Language and Audiology }\end{array}$ \\
\hline Keywords: & $\begin{array}{l}\text { Dysphagia, Deglutition, Deglutition Disorders, Swallowing, Texture } \\
\text { Modification, Thickened Liquids }\end{array}$ \\
\hline
\end{tabular}


2

3

4

5

6

7

8

9

10

11

12

13

14

15

16

17

18

19

20

21

22

23

24

25

26

27

28

29

30

31

32

33

34

35

36

37

38

39

40

41

42

43

44

45

46

47

48

49

50

51

52

53

54

55

56

57

58

59

60

\section{SCHOLARONE ${ }^{\mathrm{M}}$ Manuscripts}


Title:

Release of updated International Dysphagia Diet Standardisation Initiative Framework (IDDSI 2.0)

Running Title: IDDSI 2.0

\author{
Authors: \\ Julie A. Y. Cichero ${ }^{1,2}$ \\ Peter T. L. Lam 13,3 \\ Jianshe Chen ${ }^{1,5}$ \\ Roberto O. Dantas ${ }^{1,6}$ \\ Janice Duivestein ${ }^{1,7,8}$ \\ Ben Hanson ${ }^{1,9}$ \\ Jun Kayashita ${ }^{1,10}$ \\ Mershen Pillay 11,12 \\ Luis F. Riquelme1, 13, 14 \\ Catriona M. Steele ${ }^{1,15,16}$ \\ Jan Vanderwegen 1,17
}

\title{
Author Affiliations:
}

1. Board of Directors, International Dysphagia Diet Standardisation Initiative, Brisbane, Queensland, Australia. https://www.iddsi.org 
2. School of Pharmacy, Pharmacy Australia Centre of Excellence (PACE), The University of Queensland, Brisbane, Queensland, Australia

3. Faculty of Land and Food Systems, University of British Columbia, Vancouver, Canada

4. Peter Lam Consulting, Vancouver, Canada

5. School of Food Science and Biotechnology, Zhejiang Gongshang University, Hangzhou, China

6. Ribeirão Preto Medical School, University of São Paulo, Ribeirão Preto, São Paulo, Brazil

7. Access Community Therapists, Vancouver, British Columbia, Canada

8. Faculty of Medicine, University of British Columbia, Vancouver, British Columbia, Canada

9. UCL Mechanical Engineering, University College London, London, United Kingdom

10. Department of Health Sciences, Prefectural University of Hiroshima, Hiroshima, Japan

11. University of KwaZulu-Natal, Durban, South Africa

12. Manchester Metropolitan University, Manchester, United Kingdom

13. New York Medical College, Valhalla, New York, USA

14. New York - Presbyterian Brooklyn Methodist Hospital, Brooklyn, New York, USA

15. KITE - Toronto Rehabilitation Institute - University Health Network, Toronto, Ontario, Canada

16. Department of Speech-Language Pathology, Rehabilitation Sciences Institute, University of Toronto, Toronto, Ontario, Canada

17. Department of Speech, Language, and Audiology, Thomas More University College of Applied Sciences, Antwerp, Belgium

\section{Corresponding Author:}

Catriona M. Steele

Swallowing Rehabilitation Research Laboratory

KITE - Toronto Rehabilitation Institute - University Health Network 550 University Avenue, 12th floor

Phone: 416-597-3422

Email: Catriona.steele@iddsi.org 


\title{
Author Disclosures:
}

All authors are current members of the IDDSI Board of Directors.

\section{Acknowledgments:}

The IDDSI Board of Directors is a group of volunteers who do not draw a salary from IDDSI. They are offer their knowledge, expertise and time for the benefit of the international community.

IDDSI would like to acknowledge the interest and participation of the global community including patients, caregivers, health professionals, industry, professional associations and researchers. We also acknowledge and thank our sponsors for their generous support. Please visit https://iddsi.org/ for further information.

\author{
Abstract: \\ This letter informs readers of the release of the updated International Dysphagia Diet Standardisation \\ Initiative (IDDSI) Framework (Detailed Definitions) and Testing Methods documents, as of July 31, 2019. \\ Letter: \\ Dear Editor, \\ The International Dysphagia Diet Standardisation Initiative (IDDSI) was founded in 2013 with the goal of \\ developing new international standardised terminology and definitions to describe texture modified \\ foods and thickened liquids used for individuals with dysphagia of all ages, in all care settings, and all \\ cultures. Three years of work by the International Dysphagia Diet Standardisation Initiative Board of \\ Directors culminated in the 2016 release and 2017 publication of the IDDSI Framework, consisting of a \\ continuum of 8 levels (0-7), which are identified by numbers, text labels and color codes (Cichero et al., \\ 2017).
}


As of July, 2019 there has been widespread uptake of the IDDSI Framework around the world. Several countries have formally announced decisions to move from previous terminology to the IDDSI Framework, including, but not limited to New Zealand, the United Kingdom, Australia, Canada, the United States of America, Israel, and Ireland. Official translations of the 2016 Framework documents are available or in preparation in 28 languages other than English (https://iddsi.org/translations/). Labels on commercially manufactured products for people with dysphagia are currently in a process of transition, with many products displaying dual labelling using both previous and IDDSI terminology.

As implementation of the IDDSI Framework grows around the world, there have been many questions from different stakeholder communities including clinicians, patients and their caregivers, food service professionals, government regulatory bodies, researchers, and industry. These questions have provided opportunities for clarification and refinement and have prompted:

- the development of resources to facilitate implementation (https://iddsi.org/resources/), such as audit tools for testing and consumer handouts intended for both paediatric and adult user groups;

- a frequently-asked questions area on the IDDSI website (https://iddsi.org/faq/);

- the development of a new "Level 7 Easy to Chew", which is a sublevel of "Level 7 Regular"; and - formal review of the original framework documents.

We are pleased to notify readers that updated versions of the Complete IDDSI Framework (Detailed Definitions) and Testing Methods documents have been released as of July 30, 2019 (version 2.0) and can be accessed respectively at: http://bit.ly/2zn80rZ, and http://bit.ly/2MGgtub. 
The updated Complete IDDSI Framework (Detailed Definitions) document provides detailed descriptors for all levels of the IDDSI Framework (see Figure 1). Descriptors are supported by simple measurement methods that can be used by people with dysphagia or by caregivers, clinicians, food service professionals or industry to confirm the level a food or drink fits into. This document is to be read in conjunction with the IDDSI Testing Methods 2.0 2019, IDDSI Evidence 2016 and IDDSI Frequently Asked Questions (FAQs) documents, which can all be found on the IDDSI website (https://iddsi.org/).

\section{Ethical Statements:}

The authors of this letter to the editor are all members of the Board of Directors of the International Dysphagia Diet Standardisation Initiative. Beyond this, the authors have no conflicts of interest to declare. This letter does not pertain to any research involving either human or animal subjects.

\section{References:}

Cichero, J. A. Y., Lam, P., Steele, C. M., Hanson, B., Chen, J., Dantas, R. O., ... Stanschus, S. (2017).

Development of international terminology and definitions for texture-modified foods and thickened fluids used in dysphagia management: The IDDSI Framework. Dysphagia, 32(2), 293-314.

https://doi.org/10.1007/s00455-016-9758-y. International Dysphagia Diet Standardisation Initiative (2019). Complete IDDSI Framework (Detailed Definitions). http://bit.ly/2zn80rz

International Dysphagia Diet Standardisation Initiative (2019). Testing Methods 2.02019.

\section{http://bit.ly/2MGgtub}

International Dysphagia Diet Standardisation Initiative (2016). IDDSI Evidence 2016.

\section{http://bit.ly/2KZXOal}


International Dysphagia Diet Standardisation Initiative (2019). Frequently Asked Questions.

https://iddsi.org/faq/

International Dysphagia Diet Standardisation Initiative (2019). Translations.

https://iddsi.org/translations/

International Dysphagia Diet Standardisation Initiative (2019). Resources. https://iddsi.org/resources/ 


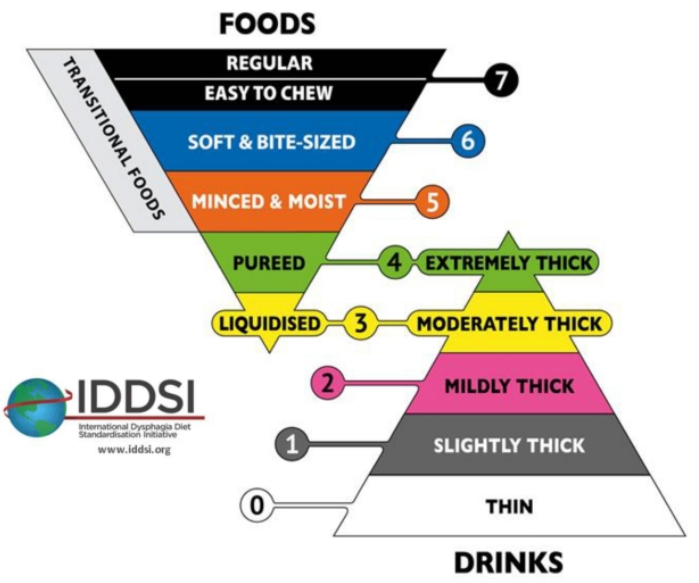

(C) The International Dysphagia Diet Standardisation Initiative 2019 @https://iddsi.org/framework.

IDDSI Framework 2.0. 2019.

$190 \times 254 \mathrm{~mm}(300 \times 300$ DPI $)$ 